\title{
Sebze Tipi Sakız Fasulyesinde Tuza Toleranslı Genotiplerin Araştırılması
}

\section{Sevim-AKÇURA ${ }^{1}$}

${ }^{1}$ Çanakkale Onsekiz Mart Üniversitesi, Lisansüstü Eğitim Enstitüsü, Tarla Bitkileri Anabilim Dalı, Çanakkale 1https://orcid.org/ 0000-0002-7699-748X

$\bowtie$ : sevimakcura@yahoo.com

\section{ÖZET}

$\mathrm{Bu}$ çalışma, 24 adet sebze tipi sakız fasulyesi (Cyamopsis tetragonoloba [L.] Taub.) genotipinin çimlenme döneminde altı tuz konsantrasyonunda (kontrol, 6, 8, 10, 12 ve $15 \mathrm{dS} \mathrm{m}^{-1}$ ) tuzluluğa toleranslarını fide kuru ağırlıklarına göre belirlemek ve toleranslı genotipleri seçmek amacıyla yürütülmüştür. Sakız fasulyesinin kuru fide ağırlığı tuz uygulamalarından önemli derecede etkilenmiştir. Tuz uygulaması, genotip, tuz uygulaması $\mathrm{x}$ genotip interaksiyonu istatistiksel olarak önemli olmuştur $(\mathrm{P}<0.01)$. Farklı tuz konsantrasyonlarına göre genotipleri değerlendirmek amaciyla regresyon analizi ve GGE biplot analizi (tuz uygulamaları = çevre) yapılmıştır. GGE biplot analizi toplam varyasyonun \%97'sini açıklamıştır. Her genotipe ait oluşturulan regresyon grafikleri ile GGE biplot grafiklerinde genotiplerin konumları birbiriyle uyumlu olmuştur. Kontrol uygulamasında yüksek ağırlığa sahip olan ve tuz uygulamalarına göre ağırlığı daha az değişen G19, G11 ve G4 genotipleri pozitif $\mathrm{PC} 1$ ve PC2 değerleri ile tuzluluğa en dayanıklı genotipler olarak belirlenmiştir. Kontrol uygulamasında yüksek kuru ağırlığa sahip olan ancak, tuz uygulamalarıyla ağırlık azalma oranı en fazla olan G12 ve G20 genotiplerine ait PC2 değerleride düşük gerçekleşmiştir. Kontrol uygulamasında düşük ağırlığa sahip olan ve tuz uygulamalarından yüksek oranda olumsuz olarak etkilenen G21 ve G22 genotipleri tuzluluğa en hassas genotipler olarak belirlenmiştir. GGE biplot yönteminde genotip seleksiyonu için kullanılan ortalama eksene göre tuzluluk eşik değeri $10 \mathrm{dS} \mathrm{m}^{-1}$ olarak belirlenmiştir. Tuzluluğa dayanıklı genotipleri belirlemek amaciyla yürütülecek araştırmalarda, regresyon analizi ile GGE biplot analizinin birlikte kullanılması araştırıcıların daha başarılı seleksiyon yapmasını sağlayacaktır.

\section{Investigation of Salt Tolerant Genotypes in Edible Cluster Bean}

\section{ABSTRACT}

This study was conducted to determine salinity tolerances at six salt concentrations (control, $6,8,10,12$, and $15 \mathrm{dS} \mathrm{m}^{-1}$ ) in the germination period of 24 vegetable type cluster bean (Cyamopsis tetragonoloba [L.] Taub.) genotypes and to select tolerant genotypes. The dry seedling weight of the gum beans was significantly affected by salt applications. Salt application, genotype, salt application $\mathrm{x}$ genotype interaction was significant $(\mathrm{P}<0.01)$. Regression analysis and GGE biplot analysis (salt application $=$ environment) were performed to select genotypes for different salt concentrations. GGE biplot analysis explained $97 \%$ of the total variation. Regression graphs created for each genotype and the positions of genotypes in GGE biplot were compatible with each other. G19, G11, and G4 genotypes, which have a high weight in the control application and whose weight varies less with the salt applications, have been identified as the most saline resistant genotypes with positive $\mathrm{PC} 1$ and $\mathrm{PC} 2$ values. $\mathrm{PC} 2$ values of G12 and G20 genotypes, which have high dry weight in control application but have the highest weight reduction rate with salt applications, were also low. G21 and G22 genotypes, which have a
Araştırma Makalesi

\section{Makale Tarihçesi}

Geliş Tarihi : 26.04 .2020

Kabul Tarihi : $\quad 30.06 .2020$

\section{Anahtar Kelimeler}

Sakız fasulyesi

Tuza dayanıklılık

Fide kuru ağırlığı

GGE biplot

\section{Research Article}

$\begin{array}{ll}\text { Article History } & \\ \text { Received } & : 26.04 .2020 \\ \text { Accepted } & : 30.06 .2020\end{array}$

\section{Keywords}

Edible cluster bean

Salt resistance

Seedling dry weight

GGE biplot 
small weight in the control application and are profoundly affected by salt applications, have been identified as the most susceptible to salinity. In the GGE biplot method, the salinity threshold value was determined as $10 \mathrm{dS} \mathrm{m}{ }^{-1}$ according to the average axis used for genotype selection. Using regression analysis and GGE biplot analysis together with researches to determine salinity resistant genotypes will enable researchers to make more successful selections.

Atıf İçin: Akçura S 2021. Sebze Tipi Sakız Fasulyesinde Tuza Toleranslı Genotiplerin Araştırılması. KSÜ Tarım ve Doğa Derg 24 (1): 99-107. https://doi.org/10.18016/ksutarimdoga.vi.727318.

To Cite: Akçura S 2021. Investigation of Salt Tolerant Genotypes in Edible Cluster Bean. KSU J. Agric Nat 24 (1): 99-107. https://doi.org/ 10.18016/ksutarimdoga.vi.727318.

\section{GİRIŞ}

Tarımsal üretimde tuzluluk problemi iki şekilde ortaya çıkmaktadır. Birincisi toprak tuzluğu, ikincisi ise sulama suyu tuzluluğudur. Uzun vadede tuzluluk tarımsal üretimde bitki verimliliği ile tarım yapılabilen arazi miktarını azalttığı için küresel bir sorundur (Scagel ve ark., 2019). Tarımsal üretim açısından tuzlu topraklar EC değeri $4 \mathrm{dS} \mathrm{m}^{-1}$ üzerinde olan topraklar olarak tanımlanmaktadır (Khalid ve Shedeed, 2014). Tarımı kısitlayan tuzluluk probleminde, toprakların tarımsal üretime uygun şekilde islah edilmesi ile tuzluluk problemi olan ve tarımsal açıdan kullanılması zorunlu olan sulama suyunun tarıma uygun hale getirilmesi oldukça pahalı bir yoldur. Ancak hem sulama suyu tuzluluğu hemde toprak tuzluluğuna dayanıklı çeşit geliştirilmesi sürdürülebilir tarım açısından en uygun yöntemdir (Flowers, 2004). Fakat bu tür koşullar için yürütülen ıslah çalışmalarının her zaman arazi koşullarında yürütülme imkânı yoktur. Bu nedenle tarımı yapılan bitkilerde hem toprak hem de sulama suyu tuzluluğuna dayanıklılık ıslah çalışmaları genellikle laboratuvar koşullarında EC iletkenliği ile ayarlanmış tuzlu sulama suyu ile çimlenme aşamasinda yapılmaktadır (Datta ve Dayal, 1988).

Tuzlu koşullara bitkilerin uyum sağlamasında en önemli faktör tohumun çimlenerek sağlıklı bir fide oluşturmasıdır. Sodyum klorür ile yürütülen bir araştırmada tuzluluk stresinin, çimlenmeyi önleyen veya geciktiren çeşitli fizyolojik ve biyokimyasal bozukluklara neden olduğu bildirilmiştir (Rehman ve ark., 1996). Ayrıca, tuzun tohumların sağllklı fide oluşturmasını çimlenme yüzdesinden daha fazla etkileyebileceğini gösteren çalışma sonuçları da vardır (Lovato ve ark., 1994).

Bitkilerin sulama suyu ve toprak tuzluluğuna karşı en hassas olduğu dönem çimlenme ve çıkış dönemidir. Çimlenerek sağllklı fide oluşturan bitkilerin tolere edebildiği tuzluluk dereceleri çimlenme aşamasındaki bitkilerden daha yüksektir (Datta ve Dayal, 1988; ElGamal, 2000).

Sakız fasulyesi tarla bitkileri içerisinde çok farklı kullanım alanına sahip ender bitkilerden birisidir. Bir araştırmada kâğıt üretiminden dondurma sanayisine kadar kullanılan 25 farklı kullanım alanı olduğu bildirilmiştir (Douglas, 2005). Değerli bir bitki olmasından dolayı, farklı çevrelerde sakız fasulyesinin yetiştiriciliği konusunda araştırmalar yürütülmektedir (Akçura ve ark., 2019). Sakız fasulyesi tarımı yapılan baklagiller içerisinde tuzluluğa en dayanıklı bitkilerden birisi olarak kabul edilir (Deepika ve Dhingra, 2014). Birçok çalışmada farklı sakız fasulyesi genotipleri tarla ve laboratuar koşullarında tuz toleransı açısından test edilmiş, bu çalışmalarda toleranslı genotipler belirlenmiştir (Vinizky ve Ray, 1988; Rosas ve ark., 1996; Deepika ve Dhingra, 2014; Iqbal, 2015; AlShameri ve ark., 2019; Jahan ve ark., 2019). Özellikle genotip sayısının yüksek olduğu durumlarda araştırıcılar çok sayıda genotipi tuzluluğa karşı kısa sürede değerlendirmek istediği zaman çimlenme döneminde çalışma yapmayı tercih etmektedir. Sakız fasulyesi genotiplerinin 200 $\mathrm{mM} \mathrm{NaCl} \mathrm{çözeltisinde} \mathrm{çimlenme} \mathrm{döneminde} \mathrm{tuzluluğa}$ dayanıklılığını belirlemek amacıyla yapılan bir araştırmada, kontrol uygulamasında \%90.3 olan çimlenme oranının, tuz çözeltisi uygulamasında \%7.7'ye düştüğü, tuzlu ortamda çimlenme oranı yüksek genotiplerin tuzluluğa dayanıklı olduğu bildirilmiştir (Teolis ve ark., 2009). Çimlenme döneminde sakız fasulyesinde tuzluluğa dayanıklı genotipleri belirlemek amacıyla yürütülen araştırmalarda $8 \mathrm{dS} \mathrm{m}^{-1}$ (Akçaman ve ark., 2017) ve 8.8 $\mathrm{dS} \mathrm{m}^{-1}$ etkilenme eşik seviye olarak belirlenmiştir (Francois ve ark., 1990; Teolis ve ark., 2009).

Regresyon analizi tuzluluğa dayanıklı genotipleri değerlendirmek amaciyla farklı bitkilerde kullanılmıştır (Kandil ve ark., 2012; Güldüren ve Elkoca, 2012; Habtamu ve ark., 2013; Lavrenko ve ark., 2019). GGE biplot analizi temelde çok farklı çevrede kurulan denemelerde incelenen kantitatif özellikleri kullanarak, hangi genotipin hangi çevreye daha iyi uyum sağladığı ve hangi çevrenin genotip seleksiyonunda daha etkili olduğu v.b. hipotezleri test etmek amacıyla kullanılan bir yöntemdir (Akçura ve ark., 2019). Bu çalışmada tuz uygulamaları çevre olarak kullanılmış, GGE biplot yöntemi ile genotiplerin tuza dayanıklılıkları değerlendirilmiştir.

Bu araştırmada, 23 adet sebze tipi sakız fasulyesi hattı ile Samen çeşidinin fide kuru ağırlığına göre sulama suyu tuzluluğuna tepkileri altı farklı tuz 
uygulamasinda [Kontrol (0.5), 6, 8, 10, 12 ve $15 \mathrm{dS} \mathrm{m}^{-}$ 1] test edilmiştir. Stres tolerans indeksi (STI) değerlerini kullanarak, regresyon analizi ve GGE biplot yöntemi ile sulama suyu tuzluluğuna toleranslı genotipler belirlenmiştir.

\section{MATERYAL ve METOT}

Çalışmada, materyal olarak kullanılan hatlar Hindistan ve Pakistan'dan temin edilen yerel sakız fasulyesi popülasyonlarından teksel seleksiyon yöntemi (G1-G23 arası olanlar) ile Çanakkale koşullarında geliştirilmiştir. $\mathrm{Bu}$ hatların yanında kontrol olarak Pakistan orijinli Samen çeşidi kullanılmış, deneme toplam 24 adet genotip ile kurulmuştur. Deneme tesadüf parsellerinde faktöriyel deneme desenine göre 3 tekerrürlü olarak yürütülmüştür.

Doğal sulama sularında en yaygın bulunan katyonlar $\mathrm{Ca}, \mathrm{Mg}$ ve Na'dır. Bazen de az miktarda potasyum bulunabilmektedir. $\mathrm{Bu}$ durum dikkate alınarak sulama suları söz konusu tuzlar kullanılarak hazırlanmıştır. Sulama sularının hazırlanmasında Sodyum Adsorbsion Oranının (SAR) 3'den küçük olması sağlanmış ve bu nedenle farklı tuz kaynakları ( $\mathrm{NaCl}, \quad \mathrm{MgSO}_{4}, \quad \mathrm{CaCl}_{2}$ ) kullanılmıştır. Sulama sularının ECi değerleri kontrol konusuna $\left(0.5 \mathrm{dS} \mathrm{m} \mathrm{m}^{-1}\right)$ ilave olarak beş farklı seviyede $\left(6,8,10,12\right.$ ve $15 \mathrm{dS} \mathrm{m}^{-}$ 1) ayarlanmıştır. Hazırlanan tüm tuz çözeltilerin EC'leri ve pH'ları EC metre ve $\mathrm{pH}$ metre ile kontrol edilmiş ve izlenmiştir.

Deneme $25 \pm 1{ }^{\circ} \mathrm{C}$ sicaklıkta, 16 aydınlık ve 8 saat karanlık koşullarda laboratuar şartlarında yürütülmüştür. Denemede her genotipten 10 [her uygulama için 3 tekerrür 30 tohum (3x10)] adet tohum, içerisinde Whatman No.1 fitre kâğıdı bulunan petri kaplarına (9 cm çapında) yerleştirilmiştir (Atak ve ark., 2006). Petri kapları içerisine $15 \mathrm{ml}$ farklı tuz yoğunluğuna sahip sulama suları konulmuş ve evaporasyonu önlemek için parafilm ile kaplanmıştır. Tohumlar petri kaplarında 7 gün laboratuvar ortaminda tutularak her gün çimlenen tohumlar sayılmıştır. Gözlemler her gün aynı saatte yapılarak en az 1'er mm uzunluğunda 1 adet sapçık ile 3 adet kökçük çıkartan tohumlar çimlenmiş olarak kabul edilmiştir. Her petri kabında çimlenen tohumlar oranlama yapılarak yüzdeye çevrilmiştir. Üçüncü günde çimlenenlerin oranı çimlenme oranı, 7. günde çimlenenlerin oranı ise çimlenme gücü olarak kabul edilmiştir.

Fide kuru ağırlıkları 7. gün sonunda her petriden elde edilen fidelerin $70^{\circ} \mathrm{C}$ de 48 saat etüvde kurutulmasindan sonra $0.00001 \mathrm{~g}$ hassasiyetli terazide tartılarak belirlenmiştir (Okçu ve ark., 2005; Kökten ve ark., 2010). Kuru ağırlığa göre oluşturulan STI değerleri ise her konsantrasyon için Rasheed ve ark., (2015) tarafından belirtildiği şekilde hesaplanmıştır.
Elde edilen veriler öncelikle her konsantrasyon için ayrı varyans analizi ile değerlendirilmiştir. Daha sonra ise genotip $\mathrm{x}$ tuz konsantrasyonu interaksiyonlarını açıklamak için birleştirilmiş varyans analizi, regresyon analizi ve GGE biplot analizleri yapılmıştır.

Biplot analizi temel bileşenler analizi ile elde edilen matrislerin (toplam varyasyonu açılama oranına bağlı olarak) grafiksel olarak gösterimidir (Gabriel, 1971). Bu nedenle eksenler PC1 ve PC2 olarak ifade edilmektedir. $\mathrm{Bu}$ çalışmada GGE biplot analizinde, genotiplerin $\mathrm{PC} 1>0.0$ değerleri tüm tuz uygulamalarında yüksek fide kuru ağırlığını ve tuz uygulamalarına toleransı, genotiplerin PC1 $<0.0$ değerleri ise düşük fide kuru ağırlığını ve tuz uygulamalarına hassasiyetini açıllamaktadır. Genotiplerin PC2 değerlerinin 0.0'a yakın olması tuz uygulamalarında stabil olduğunu, PC2 değerlerinin mutlak değerinin büyük olması ise genotiplerin tuz uygulamalarına vermiş olduğu tepkilerinin kararsız olduğunu ifade etmektedir. Ayrıca, tuz uygulamalarının vektörel uzunlukları ile ortalama tuz konsantrasyonuna göre konumları ise, genotip seleksiyonu ve kritik tuza tolerans seviyesinin belirlenmesinde kullanılmıştır. Bu çalışmada, GGE biplot yönteminde kontrol uygulaması dahil her uygulama bir çevre olarak kabul edilmiştir. Tuz konsantrasyonları çevre olarak kabul edildiği için hangi tuz konsantrasyonunda hangi genotipin daha iyi olduğu, tüm tuz konsantrasyonlarında hangi genotiplerin toleranslı olduğu, hangi tuz konsantrasyonunun genotip seleksiyonu için daha iyi olduğu, tuz konsantrasyonları arasındaki ilişkilerin nasıl olduğu, hangi genotiplerin tuz uygulamalarında hassas olduğunu tespit etmek için biplotlar oluşturulmuştur. Varyans analizleri ve regresyon analizleri SAS JMP programinda (SAS Institute, 2004), Biplot analizleri ise GGE-biplot (Yan, 2014) programında yapılmıştır.

\section{BULGULAR ve TARTIŞMA}

Genotiplerin fide kuru ağırlıkları uygulanan sulama suyu tuz seviyelerine bağlı olarak farklı seviyelerde etkilenmişlerdir. Tuz uygulaması, genotip, tuz uygulaması $\mathrm{x}$ genotip interaksiyonu istatistiksel olarak önemli olmuştur $(\mathrm{P}<0.01)$. Tuz uygulamasına bağlı olarak kuru fide ağırlıkları $0 \mathrm{dS} \mathrm{m}^{-1}$ seviyesinden $15 \mathrm{dS} \mathrm{m}^{-1}$ seviyesine doğru giderek azalmıştır (Çizelge 1, Şekil 1).

Beklenildiği gibi en yüksek fide kuru ağırlığı ortalaması $0.344 \mathrm{~g}$ olarak kontrol uygulamasinda belirlenmiştir. En yüksek fide kuru ağırlığına $0.400 \mathrm{~g}$ G4 sahip olurken bu genotipi $0.385 \mathrm{~g}$ ile G20, $0.381 \mathrm{~g}$ ile G2 takip etmiştir. Kontrol uygulamasında en düşük fide ağırlığına G21 (0.250 g) genotipi sahip olurken, bu genotipi G22 (0.254 g) ve G23 (0.289 g) genotipleri takip etmiştir. $6 \mathrm{dS} \mathrm{m}^{-1}$ tuz uygulamasında, 
genotiplerin fide kuru ağırlığı ortalaması $0.319 \mathrm{~g}$ tespit edilmiştir. Bu tuz uygulamasında en yüksek fide kuru ağırlığ G4 ve G20 genotipinde $0.365 \mathrm{~g}$ olarak, en düşük fide kuru ağırlığı $0.203 \mathrm{~g}$ olarak (G21) tespit edilmiştir. $8 \mathrm{dS} \mathrm{m}^{-1}$ tuz uygulamasında genotiplerin fide kuru ağırlığı ortalaması 0.300 g olarak belirlenmiştir. En yüksek fide kuru ağırlığına G11 genotipi $0.349 \mathrm{~g}$ ile sahip olmuştur. Bu genotip $0.338 \mathrm{~g}$ ile G14 takip etmiştir. En düşük fide ağırlığına ise $0.187 \mathrm{~g}$ ile G21 ve 0.226 ile G33 genotipleri sahip olmuştur. $10 \mathrm{dS} \mathrm{m}^{-1}$ tuz uygulamasinda genotiplerin fide kuru ağırlığı ortalaması 0.283 g olarak gerçekleşmiştir. En yüksek fide kuru ağırlığına 0.332 g ile G19 sahip olurken, bu genotipi 0.331 g ile G11 takip etmiştir. Bu tuz uygulamasında en düşük fide ağırlığına ise $0.163 \mathrm{~g}$ ile G21 ve $0.216 \mathrm{~g}$ ile G22 genotipleri takip etmiştir. $12 \mathrm{dS} \mathrm{m}^{-1}$ tuz uygulamasında genotiplerin fide kuru ağırlığ ortalaması $0.262 \mathrm{~g}$ olarak belirlenmiştir. En yüksek fide kuru ağırlığına G19 (0.320 g), en düşük fide ağırlığına ise G21 (0.152 g) sahip olmuştur.

Çizelge 1. Genotiplerin uygulanan sulama suyu tuzluluğuna göre kuru bitki ağırlıkları ve stres tolerans indeksleri

Table 1. Dry plant weights and stress tolerance indexes according to irrigation water salinity applications of genotypes

\begin{tabular}{|c|c|c|c|c|c|c|c|c|c|c|c|}
\hline \multirow[t]{2}{*}{$\begin{array}{l}\text { Genotipler } \\
\text { (Genotypes) }\end{array}$} & \multicolumn{6}{|c|}{$\begin{array}{l}\text { Tuz Konsantrasyonları }\left(\mathrm{dS} \mathrm{m}^{-1}\right) \\
\text { (Salt Concentrations })\left(\mathrm{dS} \mathrm{m}^{-1}\right)\end{array}$} & \multicolumn{5}{|c|}{$\begin{array}{l}\text { Stres Tolerans İndeksi } \\
\text { (Stress Tolerance Index) }\end{array}$} \\
\hline & 0.5 & 6 & 8 & 10 & 12 & 15 & 6 & 8 & 10 & 12 & 15 \\
\hline$\overline{\mathrm{G} 1}$ & 0.347 & 0.327 & 0.314 & 0.291 & 0.277 & 0.265 & 0.941 & 0.904 & 0.838 & 0.797 & 0.763 \\
\hline G2 & 0.381 & 0.326 & 0.308 & 0.299 & 0.282 & 0.258 & 0.855 & 0.808 & 0.784 & 0.741 & 0.677 \\
\hline G3 & 0.347 & 0.309 & 0.294 & 0.285 & 0.271 & 0.245 & 0.892 & 0.848 & 0.823 & 0.783 & 0.708 \\
\hline G4 & 0.400 & 0.365 & 0.334 & 0.320 & 0.308 & 0.280 & 0.913 & 0.835 & 0.799 & 0.769 & 0.699 \\
\hline G5 & 0.370 & 0.354 & 0.320 & 0.286 & 0.255 & 0.236 & 0.957 & 0.865 & 0.774 & 0.690 & 0.638 \\
\hline G6 & 0.321 & 0.293 & 0.276 & 0.261 & 0.239 & 0.197 & 0.914 & 0.861 & 0.813 & 0.745 & 0.614 \\
\hline G7 & 0.349 & 0.340 & 0.333 & 0.327 & 0.295 & 0.247 & 0.975 & 0.954 & 0.936 & 0.845 & 0.707 \\
\hline G8 & 0.340 & 0.316 & 0.306 & 0.292 & 0.268 & 0.234 & 0.929 & 0.899 & 0.859 & 0.786 & 0.687 \\
\hline G9 & 0.321 & 0.303 & 0.280 & 0.262 & 0.232 & 0.200 & 0.943 & 0.871 & 0.815 & 0.723 & 0.623 \\
\hline G10 & 0.333 & 0.309 & 0.257 & 0.237 & 0.220 & 0.194 & 0.928 & 0.773 & 0.711 & 0.661 & 0.583 \\
\hline G11 & 0.369 & 0.358 & 0.349 & 0.331 & 0.312 & 0.266 & 0.969 & 0.947 & 0.898 & 0.846 & 0.720 \\
\hline G12 & 0.374 & 0.337 & 0.313 & 0.275 & 0.240 & 0.180 & 0.900 & 0.837 & 0.736 & 0.640 & 0.480 \\
\hline G13 & 0.375 & 0.340 & 0.315 & 0.299 & 0.272 & 0.264 & 0.908 & 0.840 & 0.798 & 0.727 & 0.704 \\
\hline G14 & 0.367 & 0.353 & 0.338 & 0.309 & 0.296 & 0.272 & 0.962 & 0.919 & 0.841 & 0.805 & 0.740 \\
\hline G15 & 0.351 & 0.336 & 0.319 & 0.294 & 0.261 & 0.217 & 0.956 & 0.908 & 0.837 & 0.745 & 0.617 \\
\hline G16 & 0.358 & 0.338 & 0.323 & 0.311 & 0.300 & 0.276 & 0.946 & 0.902 & 0.870 & 0.838 & 0.773 \\
\hline G17 & 0.348 & 0.333 & 0.320 & 0.303 & 0.287 & 0.254 & 0.956 & 0.920 & 0.870 & 0.824 & 0.731 \\
\hline G18 & 0.348 & 0.307 & 0.286 & 0.276 & 0.264 & 0.242 & 0.882 & 0.822 & 0.792 & 0.759 & 0.694 \\
\hline G19 & 0.368 & 0.353 & 0.337 & 0.332 & 0.320 & 0.288 & 0.958 & 0.915 & 0.902 & 0.869 & 0.783 \\
\hline G20 & 0.385 & 0.365 & 0.334 & 0.304 & 0.255 & 0.201 & 0.949 & 0.869 & 0.790 & 0.662 & 0.523 \\
\hline G21 & 0.250 & 0.203 & 0.187 & 0.163 & 0.152 & 0.145 & 0.812 & 0.749 & 0.652 & 0.610 & 0.579 \\
\hline G22 & 0.254 & 0.239 & 0.226 & 0.216 & 0.193 & 0.181 & 0.943 & 0.892 & 0.853 & 0.760 & 0.712 \\
\hline G23 & 0.289 & 0.272 & 0.258 & 0.252 & 0.238 & 0.227 & 0.941 & 0.894 & 0.873 & 0.824 & 0.786 \\
\hline Samen & 0.313 & 0.287 & 0.274 & 0.260 & 0.245 & 0.230 & 0.916 & 0.873 & 0.830 & 0.781 & 0.735 \\
\hline LSD & 0.031 & 0.012 & 0.023 & 0.033 & 0.027 & 0.041 & & & & & \\
\hline Ortalama(Mean) & 0.344 & 0.319 & 0.300 & 0.283 & 0.262 & 0.233 & & & & & \\
\hline En Yüksek (Max.) & 0.400 & 0.365 & 0.349 & 0.332 & 0.32 & 0.288 & & & & & \\
\hline En Küçük(Min.) & 0.250 & 0.203 & 0.187 & 0.163 & 0.152 & 0.145 & & & & & \\
\hline Genotip & $* *$ & $* *$ & $* *$ & $* *$ & $* *$ & $* *$ & & & & & \\
\hline $\mathrm{CV}$ & 3.98 & 5.45 & 5.84 & 2.81 & 3.53 & 7.79 & & & & & \\
\hline $\mathrm{R}^{2}$ & 0.91 & 0.97 & 0.97 & 0.97 & 0.96 & 0.86 & & & & & \\
\hline
\end{tabular}



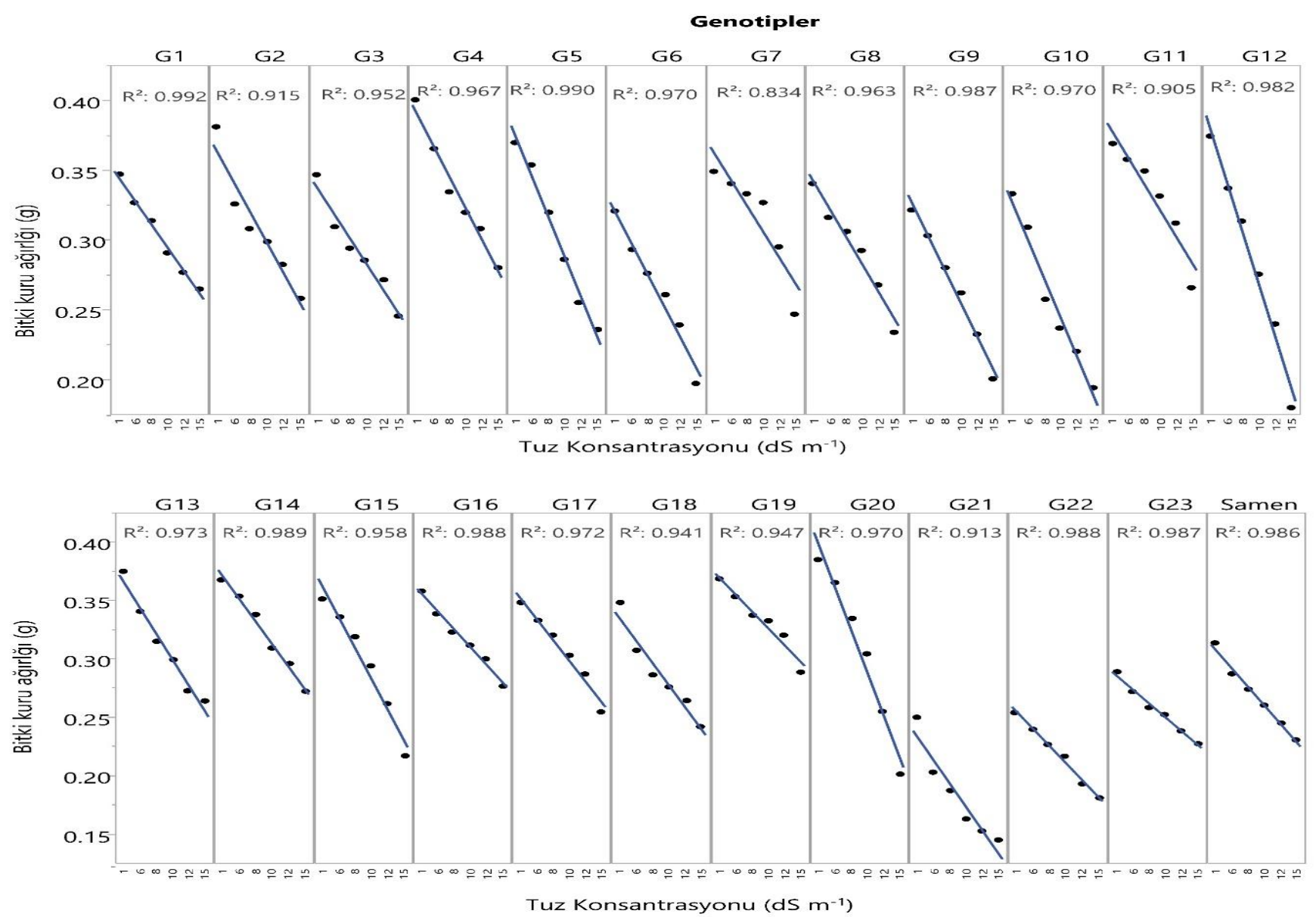

Şekil 1. Genotiplerin uygulanan sulama suyu tuzluluğuna göre kuru ağırlıklarının değişimleri

Figure 1. Changes of dry weights of genotypes according to irrigation water salinity applications

$15 \mathrm{dS} \mathrm{m}^{-1}$ tuz uygulamasinda genotiplerin fide kuru ağırlığı ortalaması $0.233 \mathrm{~g}$ olarak belirlenmiştir. En yüksek fide kuru ağırlığına G19 genotipi $0.288 \mathrm{~g}$ ile sahip olmuştur. Bu tuz uygulamasında en düşük fide ağırlığı 0.145 g ile G21 genotipinde tespit edilmiştir (Çizelge 1).

Özellikle abiyotik stres koşullarına toleranslı genotiplerin belirmenmesinde en yaygin kullanılan parametrelerden birisi STI'dir. STI'de kontrol uygulamasina göre stres uygulamalarında genotiplerin incelenen özelliklerindeki azalmalar kullanılmakta, STI değerleri yüksek olan genotipler toleanslı kabul edilmektedir (Akçura ve ark., 2011; Rasheed ve ark., 2015). Genotiplerin tuz uygulamalarına bağlı olarak oluşturulan STI değerleri Çizelge 1'de, regresyon grafikleri ise Şekil 1'de verilmiştir.

Beklenildiği gibi, $6 \mathrm{dS} \mathrm{m}^{-1} \mathrm{ECi}$ değerinden $15 \mathrm{dS} \mathrm{m}^{-1}$ ECi değerine doğru genotiplerin STI değerleri azalmıştır. Birinci tuz uygulamasında $\left(6 \mathrm{dS} \mathrm{m}^{-1}\right)$ STI değerleri G2, G3, G18 ve G21 genotipleri hariç diğer genotiplerde 0.90'nın üzerinde olmuştur. Genotiplerin STI değerlerinin tuz konsantrasyonlarına bağlı olarak değişim seyri ile regresyon grafiklerinin seyri benzer olmuştur. Tuz stresine bağlı olarak ( $6 \mathrm{dS} \mathrm{m}^{-1}$ 'den 15
$\mathrm{dS} \mathrm{m}^{-1}$ e doğru) en yüksek STI değerlerine genellikle G11, G4 ve G19 genotipleri sahip olmuştur. Tuz uygulamalarına bağlı olarak en fazla kuru ağırlık azalması G12 ve G20 genotiplerinde gerçekleşmiştir. Söz konusu genotipler en üst tuz uygulaması olan 15 $\mathrm{dS} \mathrm{m}^{-1}$ konsantrasyonunda en düşük STI değerlerine sirasıyla 0.480 ve 0.523 olarak sahip olmuştur. G21 ve G22 genotiplerinde ise regresyon doğruları en az değişim göstermiştir. Ancak, bu genotiplerin kontrol uygulamasındaki kuru ağırlık değerleri çok düşük olduğu için genotipler arasında en son sırada yer almışlardır (Şekil 1). Bu araştırmada olduğu gibi çok sayıda genotip ile yürütülen çalışmalarda, tuzluluğa tolerans açısından çimlenmedeki genotipik farklılıklar dayanıklılığın belirlenmesinde oldukça önemlidir (Saxena ve ark., 1994). Bu nedenle petride tuzlu ortamda tohumları çimlenmesi, tuzluluğa dayanıklılığı hızlı bir şekilde belirlemek amacıyla kullanılmaktadır (Jana ve Slinkard, 1976). Farklı tuz solüsyonları içeren petri kutuları kullanılarak fasulye (Goertz ve Coons, 1989; Güvenç ve Kantar, 1996; Elkoca, 1997), sorgum (Esechie, 1994), ekmeklik buğday (Kırtok ve ark., 1994) ve farklı sebze türlerinin (Cucci ve ark., 1994) tuzluluğa toleransları test edilmiş, kısa sürede dayanıklı tür ve çeşitler belirlenmiştir. 
Bitkilerde olumsuz şartlara adaptasyon yönünden en önemli özelliklerden birisi güçlü bir fideye sahip olmasıdır (Akram ve ark., 2010). Hızlı ve düzgün tohum çimlenmesi ve erken fide büyümesi, tuzlu topraklarda bitkisel üretim için hayati öneme sahiptir (Foolad, 2004; Ashraf ve ark., 2008). Sakız fasulyesi yetiştiriciliğinde bitkinin olumsuz şartlara en hassas olduğu dönem çıkış ve erken fide dönemidir (Ashraf ve Lin, 1994). Genotiplerin farklı koşullara adaptasyonunu görsel olarak en iyi değerlendirmeyi sağlayan yöntemlerden birisi GGE biplot yöntemidir.

$\mathrm{Bu}$ nedenle Sakız fasulyesi genotiplerinin tuz
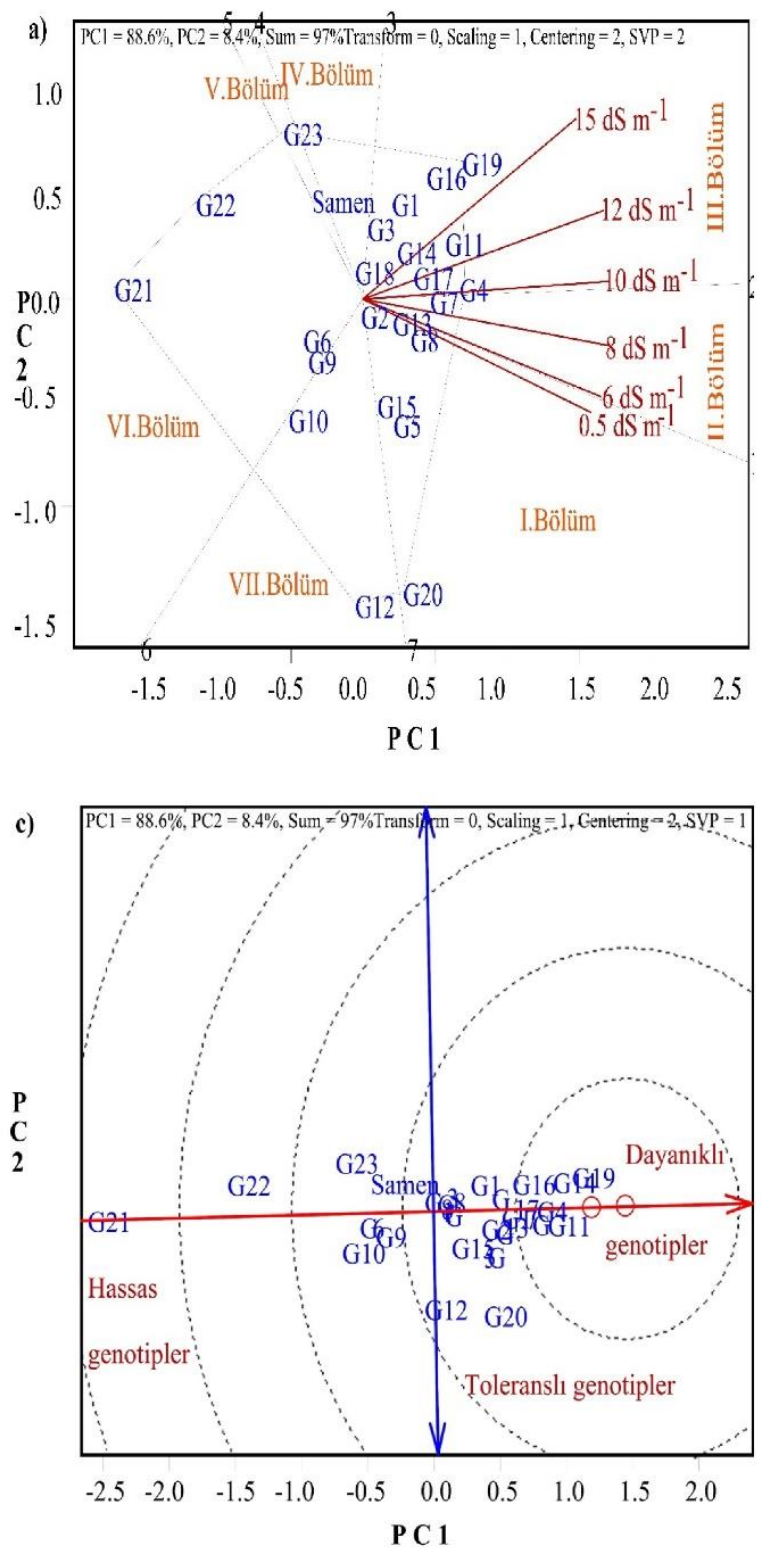

uygulamalarina tolerans düzeylerini görsel olarak değerlendirmek için GGE biplot analiz yöntemi kullanılmıştır. Hangi genotipin hangi tuz konsantrasyonunda en yüksek kuru fide ağırlığına sahip olduğunu yada hangi genotipin hangi tuz uygulamasını en iyi tolere ettiğini belirlemek için oluşturulan biplot Şekil 2a'da verilmiştir.

Biplot üzerinde yedi bölüm oluşmuştur. Tuz konsantasyonları birinci, ikinci ve üçüncü bölümlerde yer almıştır. Kontrol uygulaması $\left(0.5 \mathrm{dS} \mathrm{m}^{-1}\right)$ birinci, 6.0 ve $8.0 \mathrm{dS} \mathrm{m}^{-1}$ uygulaması ikinci, $10.0,12.0$ ve 15.0 $\mathrm{dS} \mathrm{m}{ }^{-1}$ uygulamaları üçüncü bölümde yer almıştır.
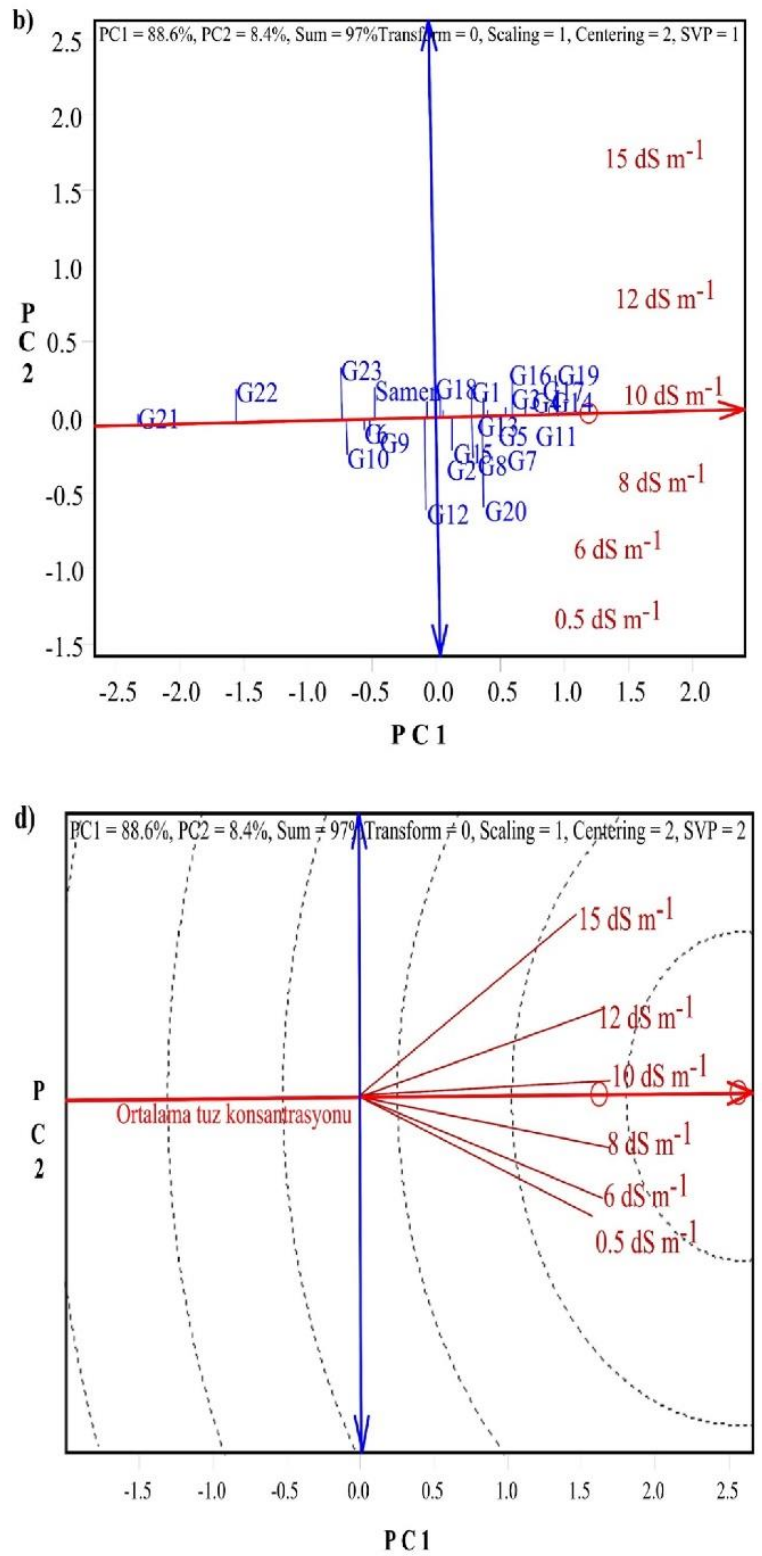

Şekil 2. Kuru fide ağırlıklarının genotip x tuz konsantasyonu etkileşimi GGE biplot grafikleri (a: poligon, b: ortalama sulama suyu tuz konsantrasyonuna göre genotip stabilitesi, c: En dayanıklı genotip, d: En uygun tuz konsantrasyonu)

Figure 2. Genotype $x$ salt concentration interaction of dry plant weights GGE biplots (a: poligon, b: genotype stability relative to the axis relative to the average irrigation water salt concentration, $c$ : The most resistant genotype, d: Optimum salt concentration) 
Genotiplerin PC1 eksen değerleri tuza tolerans düzeyine bağlı olarak artmıştır. En yüksek fide kuru ağırlığına sahip olan aynı zamanda üçüncü bölgede köşegen olarak yer alan G4, G19 ve G11 nolu genotipler en yüksek $\mathrm{PC} 1$ eksen değerine sahip olmuşlardır. PC2 eksen değerlerinde ise 0.0'a yakın olan genotipler genellikle toleranslı olmuştur. GGE biplot grafiğinde tuz konsantrasyonları arasındaki ilişkilerde görsel olarak yorumlanabilir. Vektör açılarının kosinüs değeri yaklaşık olarak iki vektörde yer alan tuz dozu arasindaki korelasyonu ifade etmektedir (Yan, 2014). Beklenildiği gibi $0.5 \mathrm{dS} \mathrm{m}^{-1}$ seviyesinden $15 \mathrm{dS} \mathrm{m}^{-1}$ seviyesine doğru gidildikçe, vektörler arasındaki açı genişlemiştir. En dar açı, 0 ile $6 \mathrm{dS} \mathrm{m}^{-1}$ seviyesinde, en geniş açı ise 12 ile $15 \mathrm{dS} \mathrm{m}^{-1}$ seviyeleri arasında gerçekleşmiştir.

Genotiplerin tüm tuz uygulamalarına vermiş olduğu tepkilerini değerlendirmek amaciyla oluşturan Biplot Şekil $2 b$ 'de verilmiştir. Şekilde görüldüğü gibi tüm tuz uygulamalarında ortalamadan yüksek değerlere sahip, ortalama tolerans eksenine en yakın olan ve pozitif $\mathrm{PC} 1$ değerlerine sahip olan genotipler G11, G4, ve G19 nolu genotiplerdir. Bu genotipler aynı zamanda tuza dayanıklılığ gruplamak amaciyla oluşturulan biplot üzerinde dayanıklı genotip bölgesinde yer almışlardır (Şekil 2c). Hangi tuz konsantasyonunun genotip seleksiyonunda daha etkili olduğunu belirlemek amaciyla oluşturulan biplot Şekil 2d'de verilmiştir. ECi değeri arttıkça genotiplerin kuru ağırlıkları da azalmıştır. Sakız fasulyesi genotiplerinin 0.0 ve $6 \mathrm{dS} \mathrm{m}^{-1}$ dozundaki kuru ağırlık değişimleri benzer olmuştur. Özellikle 8, 10, $12 \mathrm{dS} \mathrm{m}^{-1}$ seviyelerinde genotiplerin kuru fide ağırlıklarında azalmalar tespit edilmiş olsa da genel olarak bu üç seviyedeki reaksiyonlar birbirine benzemiştir. Söz konusu üç konsantrasyon arasında $10 \mathrm{dS} \mathrm{m}^{-1} \mathrm{ECi}$ seviyesi en etkin genotip seleksiyonunu sağlayan, teorik olarak hesaplanan ideal seleksiyon bölgesine oldukça yakın konumda yer almıştır. Bu durumda sakız fasulyesinde geniş adaptasyon yeteneğine sahip genotip seleksiyonunda bu üç ECi seviyesinin göz önünde bulundurulması, sebze tipi sakız fasulyesinde $10 \mathrm{dS} \mathrm{m}^{-1}$ değerinin eşik değeri olarak kabul edilmesi seleksiyon etkinliğini artıracaktır. Sakız fasulyesinde yürütülen farklı araştırmalarda $8.8 \mathrm{dS} \mathrm{m}^{-1}$ seviyesinin dayanıklı genotip seçiminde kullanabileceği bildirilmiştir (Francois et al., 1990; Teolis et al., 2009).

GGE biplot yöntemi, bitki ıslahçıları tarafindan farklı çevrelerde kurulan bölge verim denemelerinde ortaya çıkan genotip x çevre interaksiyonlarını açıklamak, farklı çevreler için genotip seleksiyonu yapmak amacıyla geliştirilen bir yöntemdir (Yan, 2014). Regresyon analizi ise stres koşullarına toleransın belirlenmesi amacıyla yaygın kullanılan bir yöntemdir. Bu çalışmada, regresyon grafikleri ile GGE biplot grafikleri genotip seçimini kolaylaştırmıştır.
Özellikle regresyon grafiklerinde tuz uygulamalarına bağlı olarak en yüksek ve en düşük fide ağırlıkları arasındaki farklılığın yüksek olduğu genotipler (G12 ve G20) biplot analizinde düşük PC2 değerlerine sahip olmuştur. GGE biplot yönteminde tuz konsantrasyonları çevre olarak kabul edildiği için hangi tuz konsantrasyonunda hangi genotipin daha iyi olduğu, tüm tuz konsantrasyonlarında hangi genotiplerin toleranslı olduğu, hangi tuz konsantrasyonunun genotip seleksiyonu için daha iyi olduğu, tuz konsantrasyonları arasındaki ilişkilerin nasıl olduğu, hangi genotiplerin tuz uygulamalarında hassas olduğu tespit edilmiştir. Bu değerlendirmeler bu araştırmanın temel amacı olan tuza dayanıklı sakız fasulyesi genotiplerinin kolaylıkla seçimini sağlamıştır.

GGE biplot yönteminde tuz konsantrasyonlarının tamamı pozitif PC1 değerlerine sahip olmuştur. Ancak, kontrol uygulaması $\left(0.5 \mathrm{dS} \mathrm{m}^{-1}\right)$ ile 6 ve $8 \mathrm{dS} \mathrm{m}^{-}$ 1 konsantrasyonları negatif $\mathrm{PC} 2$, diğer uygulamalar ise pozitif PC2 değerlerine sahip oluştur. Özellikle 10 $\mathrm{dS} \mathrm{m}^{-1}$ 'den sonra genotiplerin kuru ağırlıklarındaki değişimin hızlı bir şekilde düşmesine bağlı olarak PC2 değerlerinde önemli değişimler gerçekleşmiştir. Genel olarak değerlendirme yapıldığı zaman PC1 değerleri bakımından tuz konsantrasyonları arasında belirli bir farklılık gözlenmemiş iken, PC2 değerleri bakımından önemli farklılıklar ortaya çıkmıştır. Dolayısıyla tuz konsantrasyonu bakımından genotip seleksiyonunda PC2 ekseni PC1 ekseninden daha etkin bir şekilde genotip seleksiyonunu sağlamıştır.

Sonuç olarak, hem regresyon hemde GGE biplot grafiklerine göre G19, G14 ve G11 nolu genotipler en dayanıklı genotipler olarak belirlenmiştir. Buna ilave olarak G2, G7, G14, G16 ve G17 hatları ise toleranslı genotipler olarak tespit edilmiştir. Sebze tipi sakız fasulyesinde geniş adaptasyon yeteneğine sahip ve tuza toleranslı olan genotiplerin seçilmesi için $10 \mathrm{dS} \mathrm{m}$. ${ }^{1} \mathrm{ECi}$ değerinin seleksiyon amacıyla kullanılmasının yararlı olacağı sonucuna ulaşılmıştır. Başta sulama suyu tuzluluğuna dayanıklılık olmak üzere farklı abiyotik stres koşullarına dayanıklı genotiplerin seleksiyonunda varyans analizine ilave olarak regresyon ve GGE biplot yönteminin kullanılması araştırıcıların genotip seleksiyonlarını etkin bir şekilde yapmasını sağlayacaktır.

\section{Çıkar Çatışması Beyanı}

Makale yazarları aralarında herhangi bir çıkar çatışması olmadığını beyan ederler.

\section{Araştırmacıların Katkı Oranı Beyan Özeti}

Yazarlar makaleye eşit oranda katkı sağlamış olduklarını beyan ederler. 


\section{KAYNAKLAR}

Akçaman N, Taş I, Coşkun Y 2017. Farklı Sulama Suyu Tuzluluk Seviyelerinin Sakız Fasulyesi (Cyamopsis tetraganoloba)'nin Çimlenmesi Üzerine Etkileri. Türk Tarım ve Doğa Bilimleri Dergisi, 4(2): 130-137.

Akçura M, Turan V, Kokten K, Kaplan M 2019. Fatty acid and Some Micro Element Compositions of Cluster Bean (Cyamopsis tetragonoloba) Genotype Seeds Growing Under Mediterranean Climate. Industrial Crops and Products, 128: 140-146.

Akçura M, Partigoç F, Kaya Y 2011. Evaluating of drought stress tolerance based on selection indices in Turkish bread wheat landraces. Journal of Animal and Plant Sciences, 21(4): 700-709.

Akram M, Ashraf MY, Ahmad R, Waraich EA, Iqbal J, Mohsan M 2010. Screening for Salt Tolerance in Maize (Zea mays L.) Hybrids at an Early Seedling Stage. Pakistan. Journal of Botany, 42(1): 141-154.

AlShameri AF, Al-Qurainy S, Khan Nadeem M, AbdelRhman Gaafar A, Alameri M, Tarroum Alansi S, Ashraf M 2019. Morpho-physiological Responses of Guar [Cyamopsis tetragonoloba (L.) Taub.] to Multiple Stresses of Drought, Heat and Salinity. Journal of Botany, 51 (3): 817-822.

Ashraf M, Athar HR, Harris PJC, Kwon TR 2008. Some Prospective Strategies For İmproving Crop Salt Tolerance. Advances in Agronomy, 97: 45-110.

Ashraf M, Lin W 1994. Breeding for Salinity Tolerance in Plants, Critical Reviews in Plant Sciences, 13 (1): 17-42.

Atak M, Kaya MD, Kaya G, Kıllı Y, Çiftçi CY 2006. Effects of $\mathrm{NaCl}$ on the Germination, Seedling Growth and Water Uptake of Triticale. Turkish Journal of Agriculture and Forestry, 30: 39-47.

Cucci G, De Caro A, Ciciretti L, Leoni B 1994. Salinity and Seed Germination of Some Vegetable Crops. International Symposium on Agrotechnics and Storage of Vegetable and Ornamental Seeds. 362 pp (305-310).

Datta KS, Dayal J 1988. Effect of Salinity on Germination and Early Seedling Growth of Guar (Cyamopsis tetragonaloba L.). Indian Journal of Plant Physiology, 31(4): 357-363.

Deepika H, Dhingra R 2014. Effect of Salinity Stress on Morpho-physiological, Biochemical and Yield Characters of Cluster Bean (Cyamopsis tetragonoloba L.) Taub. Indian Journal of Plant Physiology, 19(4): 393-398.

Douglas C 2005. Evaluation of Guar Cultivars in Central and Southern Queensland. RIRDC.

El-Gamal IM 2000. Interaction Between Cobalt And Salinity on The Plant Growth. ICEHM2000, Cairo University, Egypt, 525-533.

Elkoca E 1997. Fasulye (Phaseolus vulgaris L.)'de Tuza Dayanıklılık Üzerine bir Çalışma. Atatürk Üniv. Fen Bil. Enst., Tarla Bitkileri Ana Bilim Dalı, s: 76 Erzurum, (Basılmamış Yüksek Lisans Tezi).
Esechie HA 1994. Interaction of Salinity and Temperature on the Germination of Sorghum. Journal of Agronomy and Crop Science, 172(3): 194199.

Flowers TJ 2004. Improving Crop Salt Tolerance. Journal of Experimental Botany, 55(396): 307-319.

Foolad MR 2004. Recent Advances in Genetics of Salt Tolerance in Tomato. Plant Cell, Tissue and Organ Culture, 76(2): 101-119.

Francois LE, Donovan TJ, Maas EV 1990. Salinity Effects on Emergence, Vegetative Growth, And Seed Yield of Guar. Agronomy Journal, 82: 587592.

Gabriel KR 1971. The biplot graphic display of matrices with application to principal component analysis. Biometrika, 58(3): 453-467.

Goertz SH Coons JM 1989. Germination Response of Tepary and Navy Beans to Sodium Chloride and Temperature. Hortscience, 24(6): 923-925.

Güldüren Ş, Elkoca E 2012. Kuzey Doğu Anadolu Bölgesi ve Çoruh Vadisi'nden Toplanan Bazı Fasulye (Phaseolus vulgaris L.) Genotiplerinin Cimlenme Döneminde Tuza Toleransları. Atatürk Üniversitesi Ziraat Fakültesi Dergisi, 43(1): 29-41.

Güvenç I, Kantar F 1996. Tuza Dayanıklı Fasulye (Phaseolus vulgaris L.) Genotiplerinin Belirlenmesi. SDÜ Ziraat Fakültesi Dergisi, 9(11): 144-153.

Habtamu A, Hamza IA, Eden F, Fikadu T 2013. Effect of Salinity Stress on Germination and Seedling Vigour of Chickpea (Cicer arietinum L.) Cultivars. Academia Journal of Agricultural Research, 1(9): 161-166.

Iqbal MA 2015. Cluster bean (Cyamopsis tetragonoloba L.) Germination and Seedling Growth as Influenced by Seed Invigoration Techniques. American-Eurasian J Agric Environ Sci, 15(2): 197-204.

Jahan I, Khan D, Zaki MJ 2019. Effects of $\mathrm{NaCl}$ And $\mathrm{Na}_{2} \mathrm{SO}_{4}$ Salinization on Germination and Early Seedling Growth of Fifteen Germplasms of Guar (Cyamopsis tetragonoloba (L.) Taub.)-In Vitro. International Journal of Biology and Biotechnology, 16 (2): 533-589.

Jana MK, Slinkard AE 1976. Screening for Salt Tolerance in Lentil. Lens Newsletter, 6: 5-27.

Kandil AA, Sharief AE, Ahmed SRH 2012. Germination and Seedling Growth of Some Chickpea Cultivars (Cicer arietinum L.) Under Salinity Stress. Journal of Basic and Applied Sciences, 8(2): 561-571.

Khalid KA, Shedeed MR 2014. The Effects of Saline Irrigation Water and Cobalt on Growth and Chemical Composition in Nigella sativa. Nusantara Bioscience, 6(2):146-151.

Kırtok Y, Veli S, Tükel T, Düzenli S, Kılınç M 1994. Evaluation of Salinity Stress on Germination Characteristics and Seedling Growth of 3 Bread 
Wheats (Triticum aestivum L.). Tarla Bitkileri Kongresi 25-29 Nisan 1994, Cilt I, Agronomi Bildirileri. E.Ü. Zir.Fak. Ofset Basımevi, 57-61.

Kökten K, Karaköy T, Bakoğlu A, Akçura M 2010. Determination of salinity tolerance of some lentil (Lens culinaris M.) varieties. International Journal of Food, Agriculture and Environment, 8(1): 140143.

Lavrenko SO, Lavrenko NM, Lykhovyd PV 2019. Effect of Degree of Salinity on Seed Germination and Initial Growth of Chickpea (Cicer arietinum). Biosystems Diversity, 27(2): 101-105.

Lovato MB, Martins PS, Lemos-Filho JP 1994. Germination in Stylosanthes Humilis Population in the Presence of $\mathrm{NaCl}$. Australian Journal of Botany, 42: 717-723.

Okçu G, Kaya,MD, Atak M 2005. Effects of salt and drought stresses on germination and seedling growth of pea (Pisum sativum L.). Turkish Journal of Agriculture and Forestry, 29(4): 237-242.

Rasheed MJZ, Ahmad K, Ashraf M, Al-Qurainy F, Khan S, Athar HUR 2015. Screening of Diverse Local Germplasm of Guar [Cyamopsis tetragonoloba (L.) Taub.] for Salt Tolerance: a Possible Approach to Utilize Salt-affected Soils. Pakistan Journal of Botonay, 47(5): 1721-1726.

Rehman S, Harris PJC, Bourne WF, Wilkin J 1996.
The Effect of Sodium Chloride on Germination and the Potassium and Calcium Contents of Acacia Seeds. Seed Science and Technology (Switzerland), 25: 45-57.

Rosas SB, Palacios S, Correa NS 1996. Growth and Nodulation of Cyamopsis tetragonoloba L. (guar) Under Conditions of salinity. Phyton, 58:107-114.

SAS Institute, 2004. JMP User's Guide: Version 8.01.2, SAS Institute, Cary, NC.

Saxena NP, Saxena MC, Ruckenbauer P, Rana RS, ElFouly MM, Shabana R 1994. Screening Techniques and Sources of Tolerance to Salinity and Mineral Nutrient Imbalances in Cool Season Food Legumes. Euphytica, 73: 85-93.

Scagel CF, Lee J, Mitchell JN 2019. Salinity From $\mathrm{NaCl}$ Changes The Nutrient and Polyphenolic Composition of Basil Leaves. Industrial Crops and Products, 127: 119-128.

Teolis I, Liu W, Peffley EB 2009. Salinity Effects on Seed Germination and Plant Growth of Guar. Crop science, 49(2): 637-642.

Vinizky I, Ray DT 1988. Germination of Guar Seed Under Salt and Temperature Stress. Journal of the American Society for Horticultural Science, 113(3): 437-440.

Yan W 2014. Crop Variety Trials: Data Management and Analysis. John Wiley \& Sons. 